\title{
Does migration exacerbate mental health problems?
}

\author{
Pradeep Kumar ${ }^{1}$, Aishwarya Raj ${ }^{2 *}$
}

\section{ABSTRACT}

The concept of migration is quite broad and different synonyms have been used for the people who migrate. People migrate from one place to another place for several reasons such as, education, employment opportunities and weather issues and so on. Migration is a complex phenomenon of the contemporary world where the main aim is betterment or escape from the non-favorable factors. Researchers suggest that there is a substantial burden of mental illnesses among some migrant populations. The objective of this article is to present an overview of risk factors, advantages, disadvantages and management of mental health issues related to migrants. Literature was searched on both electronic databases such as PubMed and manually. The research studies have shown that, most of the time migration is a vulnerable factor to develop Mental Health complications. Migrated people were often found to be stressed. Most of the times there is no proper preparation and no social support present for migrants. Therefore, preparing the migrants, providing them information about migration, ensuring necessary public and health services will help in prevention from expected psychological distress and would help promote mental health well-being among migrants.

Keywords: Migration, Urbanization, Mental Illness, Well- being.

H uman migration is an ancient, social and universal phenomenon that started along with the subsistence of human beings on earth. Migration is a process, which includes the people adapting and perceive a new environment which involves making decision, preparations, going through the procedure, shifting physically to another geographical area, adjusting to the local cultural needs and becoming a part of the local socio-cultural system. It can be also defined as a way to move from one place to another in order to live and work. The movement of people from their birth place/ home to another city, state or country for a job, occupation, shelter or some other reasons is called migration.

\section{Migration, Urbanization and Mental Health}

It has been seen that there is strong association between migration, urbanization and mental health. Urbanization has felicitated the process of migration, an increase has been seen in individuals migrating from rural areas to urban areas. Urbanization also helped in the process of migration. It's true that cities provide numerous opportunities for their residents and offer significant benefits including access to goods to numerous job opportunities. At the same

${ }^{1}$ Consultant, Psychiatric Social Work, State Institute of Mental Health, University of Health Sciences, Rohtak, Haryana, India

${ }^{2}$ Clinical Psychologist, AIIMS, New Delhi, India

*Responding Author

Received: June 22, 2020; Revision Received: June 25, 2020; Accepted: September 25, 2020

(C) 2020, P Kumar \& A Raj; licensee IJIP. This is an Open Access Research distributed under the terms of the Creative Commons Attribution License (www.creativecommons.org/licenses/by/2.0), which permits unrestricted use, distribution, and reproduction in any Medium, provided the original work is properly cited. 
time, high population areas can lead to tensions, stress, instabilities between demographic groups. The percentage of the population residing in urban areas which was 3.3 billion in 2007 is projected to almost double 6.4 billion by 2050 across the world. Virtually, all of the world's population growth will be absorbed by the urban areas of the less developed regions, whose population is projected to increase from 2.4 billion in 2007 to 5.3 billion in 2050 . (United Nations, 2004)

Urbanization is taking place at quite a rapid rate in India. According to 1901 census of India, population residing in urban areas was $11.4 \%$. The numbers increased to $28.53 \%$ according to 2001 census, and crossing $30 \%$ as per 2011 census, standing at $31.16 \%$. In 2017, the numbers increased to $34 \%$, according to The World Bank. A survey by UN State of the World Population report in 2007, by $2030,40.76 \%$ of country's population is expected to reside in urban areas. (https://en.wikipedia.org/wiki/Urbanisation in India). The unprecedented urbanization mainly caused by rural to urban migration is associated with poor mental health in the general population. (Ghuncha Firdaus , 2017).

\section{Impacts of Migration}

Migration has been seen to have both positive and negative impact on the lives of migrants. There are some positive impacts like; unemployment is reduced and people get better job opportunities, migration helps in improving the quality of life of people, it helps to improve social life of people as they learn about new culture, norms, value, belief systems, customs, and languages which helps to improve brotherhood among people, migration of skilled workers leads to economic growth of the area, children get better education options, the birth rate decreases and the population density is reduced etc.

The negative impacts are that (i)the loss of a person from rural areas, impact on the level of output and development of rural areas, the influx of workers in urban areas increases competition for the job, houses, health, school facilities etc.(ii) A large population puts too much pressure on natural resources and amenities (iii) It is a big environment change for a villager to survive in urban areas because of lack of natural environment or pure air. They have to pay for most things (iv) It changes the homogeneity of population in a place which makes the distribution of population uneven (v) Most migrants are completely uneducated and illiterate, therefore, they most don't qualify for employment services, lack basic knowledge and life skills.(vi) because of poverty they are unable to live a normal and healthy life.(vii) Children and adolescents growing up in poverty have less access to proper nutrition, education or health services.(viii) Migration has also increased the slum areas in cities which also has problems like unhygienic conditions, crime, pollution etc.(ix) many a times migrants are exploited.(x) Migration is one of the main causes of increasing nuclear family where children grow up without a wider family circle as well primary social support.

Regarding the health status and life-style of the older population of Thailand, the older people whose at least one child had migrated from the family had very poor physical and mental health status including exposed to chronic diseases, had poor perceived health and very poor help seeking behavior and accessing to available services compared with those whose child or children have not migrated. (Adhikari et al 2011). In South-East-Asian countries, the children whose parents were migrated to other countries, found to be less happy, less enjoyable, poor academic performance and poor resilience compared with children of non-migrant families. It shows that migration of parents has a negative impact on children's social life and health (Jordan \& Graham, 2012).

\section{Prevalence}


The prevalence rate of mental health problem in India is concerning with numerous epidemiological studies reporting it to be ranging from 9.5 to $370 / 1000$ population across the country. According to Math \&, Srinivasaraju, 2010, about $20 \%$ of the adult population in the community are affected with one or the other psychiatric disorder. Furthermore, several studies show great variation in the prevalence rates of all mental disorders between rural and urban areas. The prevalence rate was 70.5/1000 for rural areas, 73/1000 for urban areas, and 73/1000 for both rural and urban areas (Reddy \& Chandrashekar. 1998,_Ganguli HC.2000).

\begin{tabular}{|c|c|c|}
\hline Authors & year & Findings \\
\hline He and Wong & 2013 & $\begin{array}{l}24 \% \text { of the migrated working } \\
\text { women staying in cities found } \\
\text { to be mentally unhealthy }\end{array}$ \\
\hline Bhardwaj et al & 2012 & $\begin{array}{l}\text { The } 3.4 \%, 23.45 \% \text { and } 73 \% \text { of } \\
\text { the migrant were at high, } \\
\text { moderate and low risk for } \\
\text { mental illness respectively }\end{array}$ \\
\hline Bhura and Gupta & 2011 & $\begin{array}{l}\text { After } 10-12 \text { years of migration, } \\
\text { admission rate for mental } \\
\text { illness specially schizophrenia } \\
\text { were in a pick among migrants }\end{array}$ \\
\hline Adhikari et al & 2011 & $\begin{array}{l}58 \% \text { of migrated respondents } \\
\text { had at least one symptoms of } \\
\text { poor mental health }\end{array}$ \\
\hline Maggi et al & 2010 & $\begin{array}{l}\text { The native rural adolescence } \\
\text { and young adults were } \\
\text { approximately } 25 \% \text { less likely } \\
\text { to be diagnosed with acute } \\
\text { reaction to stress and } \\
\text { approximately } 10 \% \text { less likely } \\
\text { to be diagnosed with } \\
\text { depression than migrated } \\
\text { counterparts. }\end{array}$ \\
\hline Banal et al & 2010 & $\begin{array}{l}\text { Psychiatric morbidity was } \\
33.66 \text { among migrants compare } \\
\text { to non-migrants local } \\
\text { population which was } 26 \%\end{array}$ \\
\hline Krshnaveni & 2010 & $\begin{array}{l}\text { The refuse adolescence were } \\
\text { found to be coming across of } \\
\text { high stress full events, having } \\
\text { low self-esteem and emotional } \\
\text { problems. }\end{array}$ \\
\hline Arbind Raj & 2004 & $\begin{array}{l}\text { The migrants had poor mental } \\
\text { health status; very poor help } \\
\text { seeking behaviors, the somatic } \\
\text { and neurotic symptoms were } \\
\text { more prevalent among them. }\end{array}$ \\
\hline
\end{tabular}

There is a general consensus that stress-related disorders are more prevalent among refugee populations of all ages compared to the general population. Family members/relatives of refugees, migrants having legal troubles and may be at even higher risk to suffer from depression or anxiety disorders. Presence and severity of psychiatric disorders among migrants can be because of a combination of factors such as trauma during the migration 
process, stressors during resettlement, poverty or lack of social support. Services for migrants are affected by restricted accessibility. It should address cultural and linguistic barriers to and issues in the larger social environment that impact psychosocial functioning. (Rousseau \&, Frounfelker. 2019)

\section{Migration and mental health}

Approximately 90 years ago (1932), Odergaard conducted a study to know migration and its impact on mental health of migrants. His study highlighted that the people who migrated from Norwegian emigrants to Minnesota, USA were genetically predisposed to psychosis and had later developed Schizophrenia. He pointed out that when people are vulnerable to mental illnesses, they are more prone to develop disorders in subsequent to migration. It therefore highlights that migration can be a precipitating factor for mental illnesses because of the various barriers that individuals experience in the migration process and subsequent migration period (Bhugra \& Gupta, 2011).

It has found that the children who migrated from developing countries (e.g. of Maya) to developed countries (USA) had good physical growth and health, they became overweight and obese and developed an unhealthy life-style compared with local children. Smith et al 2003). The migrant adolescents have found worse mental health and highly engaged in risk behaviors compared with the native Israel counterparts (Nakash et al 2012).

The migrants of developed countries who migrated from developing and middle-income countries are recognized as, high risk group for human immunodeficiency virus/ acquired immunodeficiency syndrome (HIV/AIDS). This highlights that the phenomenon may be because of discrimination, social exclusion, language and cultural barriers, accessing the health facilities and other services at the place of destination. It reflects on the complexities of the process of migration; the individuals migrating from developing countries to developed countries are hesitant in accessing the required services including health services. More often the services are not inclusive because of which social and health related issues are more prevalent among the migrants (McMahon \& Ward 2012). Male migrants have been seen to have wider networks compared to female. However, both of them have attributed their perceived lack of integration to the attitude of the host society and have identified broader and stronger social networks as an important source of psychological support. (Farooq et al 2005, Cohen S et al 2003, Uchino BN 2006, Hogen et al 2005, House et al 2003, Seeman T 2001). Educated households had better employment opportunities and feel better adjusted than others. They also had stronger aspirations to integrate into the host society (Patel et al 2001, Patel \& Kleinman 2003).

\section{Studies conducted in India}

The situation in India is not different from the rest of the world. A process of rapid urbanization has already been making strides in the form of the growth of big cities and urban agglomerations due to poverty induced rural-urban migration. According to Kingsley Davis urban misery and rural poverty exist side by side. He has named this phenomenon as "over-urbanization". In $21^{\text {st }}$ century the movement towards urban living has become one of the most important global health issues. More recently, there is ample evidence indicating toward increasing mental health problems in urban centers of developing countries (Harpham \& Molyneux, 2001).

In the cross-sectional survey of people living in Sangam Vihar, New Delhi, the slum residents where majority of them have migrated from other states of India were found to be 
at risk for mental illnesses. They often have nil or poor social support, interpersonal issues with other members of the family, increased worry about health, angry issues and irritability, lack of satisfaction about the living condition etc. were found to be the major findings indicating poor psycho-social health status of the internally migrated population (Bhardwaj et al 2012).

A major chunk of migratory quarry workers were seen to exhibit a variety of somatic and neurotic symptoms for a long period of time. They had almost nil to poor awareness about their mental health as well as had a very poor help seeking behavior. (Aravindraj 2004)

The refugee children from Sri Lanka staying in residential schools in Bangalore, often have a number of high stressful life events; few of them have witnessed the violence, or have lost parent/s. These children exhibit adjustment difficulties to the environment, have a low selfesteem and emotion management difficulties. They have high psychological and social distress, which indicates them to have a poor mental health status (Krishnaveni 2010).

The psychiatric morbidity was more (predominantly depression, post-traumatic stress disorder and generalized anxiety disorders) among Kashmiri migrants (33.66\%), who were staying in Muthi camp at Jammu, compared with non-migrants (26\%). The major observation of the study is that, there is a need for improving the socio-economic status of migrants and providing them effective psychiatric services (Banal et al 2010).

The occurrence rate of psychiatric disorders among migrated refugee population (who came to India after partition) of Lucknow was $9.6 \%$ compared with non-migrant local population, which was $4.2 \%$. The psychiatric patients (majority was suffering from psychoneuroses, depression and enuresis) among the migrated group were been suffering for $>10$ years and mostly belong to older aged group (Sethi et al 1972).

\section{Migration positively associated with the wellbeing of migrants}

Migration has also been seen to have positive impact on migrants. It was seen to improve social and mental health status of migrants, who migrated to New Zealand form Tonga as compared to the natives. This impact was significantly seen with respect to women and the group having lower mental health status in the country of origin. Factors such as good employment opportunities, living as permanent residents for longer periods ( $<3$ years), joining family members and/or community members, better public health services such as health facilities, education facilities and less cultural restrictions could have played part in improving the mental health of migrants in new destination (Stillman et al 2009).

\section{Management of issue related to migration}

The International Organization for migration has been involved in formulating and implementing varieties of activities and programs to help the migrant population. These activities are Resettlement and repatriation services of refugees, assisted voluntary return and reintegration program, Counter trafficking services, Immigration and visa support service, Recruitment and employment facilities, Migration training program, Migration health assessments and travel assistance service, Health promotion, Migration health assistance to crisis-affected population and so on etc.

There are many countries have started services for migrants such as trans-cultural mental health units in Paris, Bordeaux, Strasbourg etc., units for victims of torture and forced exile started by Paris, Marseille, Lyon etc., The global forum on migration and development, 
regional consultative processes on migration, improvements in the protection of migrants' rights by International Labor Organization and so on programs have started world-wide in order to reduce the psychological and social distress among migrants.

However, in spite of the availability of services to migrants the accessibility of the available services from the migrants is very poor. It shows there are many barriers, which are blocking them in accessing such services. These barriers are mainly such as, cultural and linguistic barriers, belief in non-medical interventions, the necessity of producing legal documents and fulfilling the eligibility criteria for accessing health care services and poor help seeking behavior. It is very important to address these hurdles in order to address the psycho-social and health issues of the migrants.

\section{Community based interventions}

Some of the research studies have tried to respond to the tribulations of the migrants through drawing the interventions at community level. One of the research studies states that, "there is a need for change in delivering services to the migrant population in distress; the cottagebased-model found to be more effective than traditional health care delivery to the geriatric long-term care residents during the migration. The consumers, their family members and the staffs have felt that the model is more helpful in improving the health status, social activities of the consumers (Thistleton et al 2012)

The community based intervention which involves "community mobilization" and "comprehensive voluntary counseling and testing services" among migrated rural community of Shanghai has proved a significant improvement in the promotion of voluntary HIV counseling and testing (VCT) acceptance and utilization, knowledge about HIV/AIDS, positive attitude towards HIV positive individuals and condom use compared with the traditional VCT services. (Zhang et al 2013) Along with the policies, practices and resettlement opportunities, the existence of ethno-cultural organizations and religious institutions are highly important in supporting migrants through the process of adaptation in new social, religious and legal aspects. Often these ethnic communities and religious organizations welcome migrations and help them provide a sense of belongingness, try to reduce the impact of loss, work on issues of discrimination and isolation as well (Beiser M., 2009). Therefore, it is very important for the administration or local bodies to support, recognize and enhance networking among the existing communities and religious organizations to initiate the provision of necessary resources and psycho-social support for the migrants (Reitmanova \& Gustafson 2009).

\section{Group based interventions}

The "self-help group (SHG)" and "Cognitive Behavior Therapy" group interventions were found to be partially useful among the migrated women who were diagnosed with recurrent depressive disorder. During the group intervention sessions, family affairs and difficulties in pertaining to their husbands and children need for social networks, dealing with loneliness, being unable to meet with the demands of the day to day life, were the main issues discussed as the members preferred. The group interventions found to be useful in symptom reduction, increased amount of mutual trust among the members, acquiring problem solving skills and regaining their strengths. Most of the members also expressed their will to continue the group meetings informally during the follow-up. Many respondents were disappointed with the way the therapy was offered. Results suggest that culture sensitive approach by ethnic, same gendered professional at an individual level was found to be more useful (Renner \&, Berry 2011). 
Along with cognitive behavioral therapy and SHG therapies such as 'eye-movementdesensitization, psychodrama and reprocessing forms of group interventions have also been utilized for the migrant populations having mental health difficulties such as post-traumatic stress disorder, depression and others. They were found to be helpful to an extent in improving the functionality and reducing the symptoms (Sertoz, 2005).

The above studies try to prove the efficacy of different strategies and strongly suggest the need for formulating a variety of/combination of interventions such as, administrative, legislative, group and community based intervention to help address the distress and ameliorate psycho-social issues of migrants. The intervention strategies have to be formulated at the individual level, local level, community level, policy level and national or international level; the local and international organizations, governments and the individuals, every one's efforts are crucial here. The inclusion of these services along with mutual respect for different cultures is vital as well.

\section{Suggestions}

There are some suggestions required when we interacting to migrated like using cultural formulation while dealing with psycho-social issues of migrants, establishing therapeutic alliance and trust, making services inclusive and accessible, good quality interpreter services, appropriate training for clinicians and interpreters, improving health literacy, developing participatory and collaborative partnerships with the migrant populations, achieving cultural competence etc.( Kirmayer et al 2007, Lindert et al 2008)

Migration is a process, which has it its own unique distresses. Some of these specific distresses are difficulties in communication due to language barrier and cultural differences, history of any adverse experiences in the past, during and after migration, belief system, traditions, pattern of coping, non-favorable familial dynamics, traditional beliefs, coping patterns and socio-economic status of the family hence migrants may not be prepared enough for these unexpected distresses. It is universal truth that migrated person have certain psychological distress. Therefore, the clinicians need to be trained and equipped enough to address these issues. They have to inquire systematically and scientifically-the whole process of migration, social, vocational and family aspects of functioning, cultural background, socio-economic status, comparing pre-migration to post migration status etc. This exercise will help in understanding and identifying the problems in adapting to the new environment as well as specific particular society. The clinicians should take assistance of trained interpreters and culture brokers; they may also meet the other family members for thorough information and should make use of the existing community organizations of the particular ethnicity. These strategies will help the clinicians/policy maker/administrator to identify the stressor or the problem, formulate the appropriate intervention/treatment strategy, prevent the psycho-social distresses and promote the psycho-social wellbeing of the migrants. (Kirmayer et al 2011)

\section{CONCLUSION}

Migration is a contemporary, complex phenomenon in which the main intention is betterment or escaping from the non-favorable factors. Migration need not to be stressful all the time, but when there is no proper preparation and no social support, complexities present, barriers and differences involved, there will be definite distress; no matter whether it is international or internal migration. Generally, most of the time migration is a vulnerable factor to develop Mental Health complications. There are some reasons behind this such as- 
feelings of insecurity and non-availability of own community members. These distresses would turn into mental health consequences or other forms of health complications. There is urgent need of making avail, accessible and affordable of the public and health services. The services should be inclusive, culture specific and culture free, providing necessary training for the personnel. Trained interpreters should be available in all the levels. These interpreters will provide the information about migration, preparing the migrants, ensuring the necessary health. Such kind of public services will help in preventing expected psychological distress and promoting mental health well-being among migrants. There is a wide scope for research studies to investigate further to have in-depth understanding of the pattern of mental health problems and formulating more effective intervention strategies in preventing the distress and promoting the psycho-social well-being of the migrants.

\section{REFERENCES}

Adhikari R, Jampaklay A, Chamratrithirong A. Impact of children's migration on health and health care-seeking behavior of elderly left behind. BMC Public Health. 2011; $11: 143$.

Aravindraj E. Bangalore: NIMHANS Deemed University; 2004. Psychosocial Profile of Migratory Quarry Workers.

Banal R, Thappa J, Shah HU, Hussain A, Chowhan A, Kaur H, et al. Psychiatric morbidity in adult Kashmiri migrants living in a migrant camp at Jammu. Indian $J$ Psychiatry. 2010; 52:154-8.

Beiser M. Resettling refugees and safeguarding their mental health: Lessons learned from the Canadian Refugee Resettlement Project. Transcult Psychiatry. 2009; 46:539-83.

Bhardwaj U, Sharma V, George S, Khan A. Mental health risk assessment in selected Urban Slum of Delhi - A survey report. J Nurs Sci Pract. 2012; 1:1

Bhugra D, Gupta S, editors. New York: Cambridge University Press; 2011. Migration and Mental Health.

Cohen S. Psychosocial models of the role of social support in the etiology of physical disease. In: Salovey P, Rothman AJ, editors. Social Psychology of Health. New York: Psychology Press; 2003. pp. 227-44.

Farooq M, Ahmad M, Cheema MA. Elderly migrants adjustment problems in the urban areas. J Agric Soc Sci. 2005; 3:283-4.

Ganguli HC. Epidemiological findings on prevalence of mental disorders in India. Indian J Psychiatry. 2000; 42:14-20.

Ghuncha Firdaus: Mental well-being of migrants in urban center of India: Analyzing the role of social environment. Indian J Psychiatry 2017 Apr-Jun; 59(2): 164-169.

Harpham T, Molineux C. Urban health in developing countries: A review. Progress in Development Studies. 2001; 1:113-37. https://en.wikipedia.org/wiki/Urbanisation in India Retrieved on 27.05.2020..

He X, Wong DF. A comparison of female migrant workers' mental health in four cities in China. Int J Soc Psychiatry. 2013; 59:114-22.

Hogan BE, Linden W, Najarian B. Social support interventions: Do they work? Clin Psychol Rev. 2002; 22:383-442.

House JS, Landis KR, Umberson D. Social relationships and health. In: Salovey P, Rothman AJ, editors. Social Psychology of Health. New York: Psychology Press; 2003. pp. 218-26.

Jordan LP, Graham E. Resilience and well-being among children of migrant parents in South-East Asia. Child Dev. 2012; 83:1672-88. 
Kirmayer LJ, Narasiah L, Munoz M, Rashid M, Ryder AG, Guzder J, et al. Common mental health problems in immigrants and refugees: General approach in primary care. CMAJ. 2011;183: E959-67.

Kirmayer LJ, Weinfeld M, Burgos G, du Fort GG, Lasry JC, Young A. Use of health care services for psychological distress by immigrants in an urban multicultural milieu. Can J Psychiatry. 2007; 52:295-304.

Krishnaveni V. Bangalore: NIMHANS Deemed University; 2010. Psycho-social Profile of the Adolescent Refugees.

Lindert J, Priebe S, Penka S, Napo F, Schouler-Ocak M, Heinz A. Mental health care for migrants. Psychother Psychosom Med Psychol. 2008; 58:123-9.

Maggi S, Ostry A, Callaghan K, Hershler R, Chen L, D'Angiulli A, et al. Rural-urban migration patterns and mental health diagnoses of adolescents and young adults in British Columbia, Canada: A case-control study. Child Adolesc Psychiatry Ment Health. 2010; 4:13.

Math SB, Srinivasaraju R. Indian psychiatric epidemiological studies: Learning from the past. Indian J Psychiatry. 2010;52(Suppl 1): S95-103.

McMahon T, Ward PR. HIV among immigrants living in high-income countries: A realist review of evidence to guide targeted approaches to behavioural HIV prevention. Syst Rev. 2012;1:56.

Nakash O, Nagar M, Shoshani A, Zubida H, Harper RA. The effect of acculturation and discrimination on mental health symptoms and risk behaviors among adolescent migrants in Israel. Cultur Divers Ethnic Minor Psychol. 2012; 18:228-38.

Patel V, Abas M, Broadhead J, Todd C, Reeler A. Depression in developing countries: Lessons from Zimbabwe. BMJ. 2001; 322:482-4.

Patel V, Kleinman A. Poverty and common mental disorders in developing countries. Bull World Health Organ. 2003; 81:609-15.

Reddy MV, Chandrashekar CR. Prevalence of mental and behavioral disorders in India: A meta-analysis. Indian J Psychiatry. 1998; 40:149-57.

Reitmanova S, Gustafson DL. Mental health needs of visible minority immigrants in a small urban center: Recommendations for policy makers and service providers. J Immigr Minor Health. 2009; 11:46-56.

Renner W, Berry JW. Group Interventions were not Effective for Female Turkish Migrants with Recurrent Depression - Recommendations from a Randomized Controlled Study. Soc Behav Pers. 2011; 39:1217-34.

Rousseau C, Frounfelker RL. Mental health needs and services for migrants: an overview for primary care providers: J Travel Med. 2019 Feb 1;26(2).

Seeman T. How do others get under our skin? Social relationships and health. In: Ryff CD, Singer BH, editors. Emotion, Social Relationships, and Health. New York: Oxford University Press; 2001. pp. 189-210.

Sertoz OO, Mete HE. Obezite Tedavisinde Bilissel Davranisci Grup Terapisinin Kilo Verme, Yasam Kalitesi ve Psikopatolojiye Etkileri: Sekiz Haftalik İzlem Calismasi [Efficacy of cognitive behavioral group therapy on weight loss, quality of life and psychopathology in the treatment of obesity: Eight-week follow-up study. Klinik Psikofarmakoloji Bülteni. 2005; 15:119-26.

Sethi BB, Gupta SC, Mahendru RK, Kumari P. Migration and mental health. Indian J Psychiatry. 1972; 14:115-21.

Smith PK, Bogin B, Varela-Silva MI, Loucky J. Economic and anthropological assessments of the health of children in Maya immigrant families in the US. Econ Hum Biol. 2003; 1:145-60. 


\section{Does migration exacerbate mental health problems?}

Stillman S, McKenzie D, Gibson J. Migration and mental health: Evidence from a natural experiment. J Health Econ. 2009; 28:677-87.

Thistleton W, Warmuth J, Joseph JM. A cottage model for eldercare. HERD. 2012; 5:99_ 114.

Uchino BN. Social support and health: A review of physiological processes potentially underlying links to disease outcomes. J Behav Med. 2006; 29:377-87.

United Nations. World Urbanization Prospects: The 2003 Revision. United Nations. 2004. Available

from: http://www.un.org/esa/population/publications/wup2003/2003Highlights.pdf.

Zhang T, Tian X, Ma F, Yang Y, Yu F, Zhao Y, et al. Community based promotion on VCT acceptance among rural migrants in Shanghai, China. PLoS One. 2013;8: e60106.

\section{Acknowledgements}

The author appreciates all those who helped to facilitate the research process.

\section{Conflict of Interest}

The author declared no conflict of interest.

How to cite this article: P Kumar \& A Raj (2020). Does migration exacerbate mental health problems? International Journal of Indian Psychology, 8(3), 32-41. DIP:18.01.005/20200803, DOI:10.25215/0803.005 